\title{
An Analysis: Productivity Improvement in Printing Industry
}

\author{
Jatin Haresh Varma, Sachin Lal
}

\begin{abstract}
This study was conducted to investigate factors associated with improving productivity in printing. One way to improve productivity is by minimizing the end result of the printing scrap due to manual problems before printing or technical problems during printing and some after printing problems. This paper provides a survey of techniques and actions such as characteristics of the paper surface, paper quality, productivity, hardware such as circuit boards, volume and other factors. Six Sigma is an approach that helps to improve the quality of the output and is used to identify proper system settings that can help with good strength to produce the requiredparts.
\end{abstract}

Keywords : Printing, manufacturing, style, styling, pigment, six sigma.

\section{INTRODUCTION}

There are various machinery built specifically for the printing industry with advances in technology. During the process, there are different types of scraps in the printing industry that need to be handled and minimize resource waste. This is necessary to increase the organization's percentage of productivity and profit. In this paper, therefore, we will discuss the need to increase the productivity of printing by considering different literatures and suggest one of the best approaches.

Six Sigma is a technique that Motorola developed in 1986. It is used for quality control that focuses on circulation and timely improvement with minimizing malfunction or defects during the production process until it reaches more than 3.4 parts per million. When we see in the current scenario, Six Sigma evolves more into business management with the goal of fulfilling any customer requirements, improving customer relationships, improving product and services, improving and sustaining business. Six Sigma is a technique that should be followed by all companies. Six Sigma's focus is primarily on statistical improvement. Six Sigma team is present for any quality control and success rate measurement. For all statistical work, Six Sigma is the criteria. Process is considered efficient in any production department that produces fewer than a few defects per million. The term defect is called when a product is produced outside the specifications given by the desired product or outside the satisfaction of theconsumer.

Standard Six Sigma method consists of an approach of five

Revised Manuscript Received on July 22, 2019.

Jatin Haresh Varma, Dr. Sachin Lal 1PhD Scholar

Professor Mechanical Engineering, Sir Padampat Singhania University,

Udaipur, India , atin.varma @ spsu.ac.in, 2sacin.lal@spsu.ac.in steps i.e. DMAIC (Defining, measuring, analyzing, improving and monitoring). DMAIC's concept is to solve product development issues in the industries. There are certain things to follow for this. In Define module, Six Sigma expert group of people find an inefficient or faulty process. Then decisions are made after analyzing the specific mission and vision of the company. This helps to list the project's problem, objectives and what to deliver. Next is to measure the process's initial performance. This helps to list things that can create the problem and help understand the results of the target. Next process analysis by isolating each cause, any small or large priority reason that causes the process to fail. If it is root of that problem, then work

on test cases after that. Based on these results analysis, any process fault is identified. The group then looks to improve overall system performance after this is done. Lastly, the group attaches control to the process to ensure that it does not ultimately create any problems andunproductivity.

Digitalization and technology modernization enabled the customer to be highly selective about the product / services. This scenario has created a competitive environment for both manufacturing (such as printing) and service industries. The organizations are adopting the business excellence practices in order to make the business profitable in such a dynamic environment. The plant rolls out annually in an average of 550 Million pages. The plant consumes 2390 metric tons (MT) of printing per year, 3.9 lakhs of power and 48 MT of inks per year. Printing costs have been increased by the complex and dynamic developments in the business environment. High production costs are very critical concerns for any organization in today's cut-throat business competition. Increased $\mathrm{CO} 2$ emissions, power consumption and water consumption as well as increased printing scrap. This organizational scenario shows the need for productivity improvement and reduction of waste and productioncosts.

\section{LITERATURE SURVEY}

\subsection{Literature Survey on PrintingIndustry}

Author[1] explained that paper quality with pigment is widely accepted in thepaper printing industry today. Pigments on the surface of mechanical parts are used for transfer printing. End results show that paper coating has helped reduce the roughness of paper. Compared to uncoated paper, the mechanical properties are improved by coating. There is also a presence of plastic pigment to improve the quality of paper. The coated paper's optical 
density is greater. An investigation to generate new printing from old paper was conducted. If a paper has more plastic, the optical density will increase. Authors found that coat paper had a low dye content comparedtonocoatpaper.Andmakingsecondprintwithhigher opticaldensity.

Author[2] discusses the quality of the surface to the eyes. To check different surface properties, sample black and white printing is taken. Testing is carried out using different machines for all types of papers and samples printed. If there is low rough, optical density is more compatible with print quality. If the gloss of paper is low, the quality of the print will improve. If the paper's color metric value is changed, the color of the output samples is of low importance compared to the samples printed with higher opticaldensity. Author[3] discusses that the quality program faces different challenges as well as difficulties in producing results. Authors examined the limit to which three key variables are employee development, empowerment and participation (EDEP) used to determine the success rate in printing plants. Authors collected data from several Ghana-based printing firms. There are some questions in the category of development, empowerment category and employee participation for monitoring and evaluating the practices in firms. To achieve a quality goal, descriptive and multiple series of analysis are required to maintain the relationship of variables. EDEP is actually linked to the achievement of printing quality. Participation that contributes more to quality achievement is more effective from the three variables given. After thisempowermentcomesintoview, whichhasadirectimpactonq ualityevaluation.

\subsection{Literature Survey onProductivity}

Productivity as the ratio between output and input can be improved by varying output and input in the industrial scenario. Production is an important attribute to the productivity deviation. Some work cultures were introduced by researchers that helped improve productivity and may have some positive effects on employment.

Author[4] explained about outsourcing, which contributes to capacity scarcity growth and production improvement. Using the quantity rate and different processes, the production process is found. Data analysis takes into account many criteria and evaluates the efficiency of manufacturing processes to assist in the use of industrial products. Authors used the Malmquist productivity index (MPI) to check the change in production in every process that requires external action. Authors also discuss decision parameters with lower value and higher value of MPI. The result shows that the manufacturing process can ensure less efficient value with very high savings of available resources.

Authors[5] explained the labor output in assembly module focusing on advanced supplier module study. Author explains that modular assembly is applied to all builders of automotive and body parts to handle automotive companies ' dynamic change in requirements. With many SCM (Supply Chain Management) research and time recorded features under module generation. Authors created mathematical models together with the overall work of two concepts of the assembly line, i.e. box line and conveyor line. Considered two productivity scales: high output and normal output. The labor productivity rates are obtained from calculations as a performance indicator and different tests arecompared.

Author[6] investigated that sales volume increase improved overall machine equipment efficiency (OEE). The manufacture of industrial factories helped the Indian industries. Currently, the manufacturing industry is in dire need of proper functioning for survival and prosperity in this competitive environment. For instant and linear improvement in the manufacturing department, this practice in all industries increases. OEE provides a better control tool to improve the disadvantages of production and operation. Productivity and cost of manufacturing are considered vital characteristics of performance assessment. By using TPM initiatives with interactive research techniques, authors conducted various analyzes and evaluations to increase sales. There is an OEE tool in industry that has a high potential to improve the efficiency of the equipment. It was observed that new OEE with low cost of production helped to increase sales revenue and boost profit for the coming years. It was also noted that the industry benefited from the use of TPM implementation.

\subsection{Literature Survey on Six Sigmaimplementation}

Author[7] explained the increasing operation of the company. By using Six Sigma tools, line assembly failures can be reduced and customer relationships can be improved. Some changes such as hydraulic oil, grinder and cutter check and change if necessary in the improvement phase. Ultimately on - the-spot problems dropped by more than 90 percent, resulting in very good cost savings. Authors found that using the methodology of Six Sigma DMAIC in Indian farms reduced field failures and improved customer relations.

Author[8 ] provides a survey of the product's frequency analysis. Knowing the importance of CSFs and zones is being done. There have been a number of CSFs falling into zone of danger, semi - safe and safe zone.

Author[9] provides a survey and proposes a six-sigma project selection process framework approach and lists different recent tools and methodsneeded for each stage. Authors specified that their objective is to identify the importance of the approach to the project portfolio. The study used a process framework approach and a systematic review of literature to identify and classify different literature related to six sigma projects and their associated tools and methods. The paper provides broad insights into the possibility and direction of future Six Sigma project research. In the field of research, expert opinion is always needed to validate it. With this analysis and expert opinions, new researchers will definitely benefit from learning Six Sigma techniques and issues for their interest in research. Second, industry practitioners and consultants working in the Six Sigma area may be working to make Six Sigma more successful.

\subsection{ResearchGaps}

Many researchers are working for manufacturing and construction industries to improve productivity. They used various tools and techniques toimproveanindustry that implemented them.It should be 
noted that six sigma approaches are needed to improveproductivity.

Foreign businesses are already using these techniques to achieve perfection at all levels in their business processes. This is high time, therefore, when all workers should be trained with proper Six Sigma certification along with management in order to implement the same in Indian processes.

\section{SIX SIGMA APPROACH}

Six Sigma approach involves understanding and controlling key process variables or input types in order to achieve nice improved results. Six Sigma's DMAIC approach is used as a baseline approach under this area of work. DMAIC tells of the steps to be taken. This is done by starting with the real identification of problems and finding a very long-term solution. This is shown in the Figure 1 flowchart. DMAIC's goal is to make the printer's body parts and find the best setting resulting in less waste.

Activity 1 (Define): The projects from different departments will be identified in this activity. To prioritize the identified project, the different methods will be identified. Choose the appropriate prioritization method. The expected result of this activity is to select suitable research project.

Activity 2 (Measure): The project will be critically analyzed in this activity to understand the system and explore the areas of pain. At this research stage, the data collection plan will be developed in conjunction with the data collection checklist. Based on the checklist, the data will be collected and analyzed with appropriate tools to check the current process stat us.

Activity 3 (Analysis): Identify the method for investigating the potential causes of rejection in this activity. Choose the appropriate method and identify potential pain area causes. Prioritized potential causes identified using the appropriate method.

Activity 4 (Improve): Identify the various methods for developing the action planin this activity and select the appropriate method for developing the action plan. Develop the improvement action plan to optimize it and make it cost-effective.

Activity 5 (Control): Implement the plan of action for improvement in this activity. Collect the data on the basis of the check sheet after implementation. After improvement, the data collected was analyzed. If the results are positive, the action plan will be modified and the defined target will be achieved.

Printing steps are shown in the Fig flow chart. 2 Beginning with the collection of information. Information may come from replies, reporters, photographers, etc. Then design the page consisting of state-of - the-art technology software with built- in and custom features. Designing of the plate after this phase of printing takes place. Here computers help with special patterns, color, font and plate dimensions when designing the plate. After this initial task, the product goes to print where high-quality machines for color printing are used. After this is done, printed pages are counted and dispatch stacking is done. Instead of using automatic machinery for time-saving purposes and without any error,

counting and stacks are not done by humans. After that, the pages in transportation vehicles are strapped and dispatched. Transportation vehicles are arranged for transportation to various sectors, areas in a state. This printed copy is delivered to the end user, i.e. the common man who is the printed paper reader and gains knowledge from it. The scrap comes from the factory where the pages are printed, as we can see in this diagram. Any minor error leads to paper wasting. This can occur in any phase described in Figure 2. To minimize this, it is necessary to follow many rules and instructions. Besides that it is necessary to keep better settings in the machinery so that waste of resources such as ink, paper,

heating, compression, folding papers, counting, dispatch to the right place is handled with utmost care.

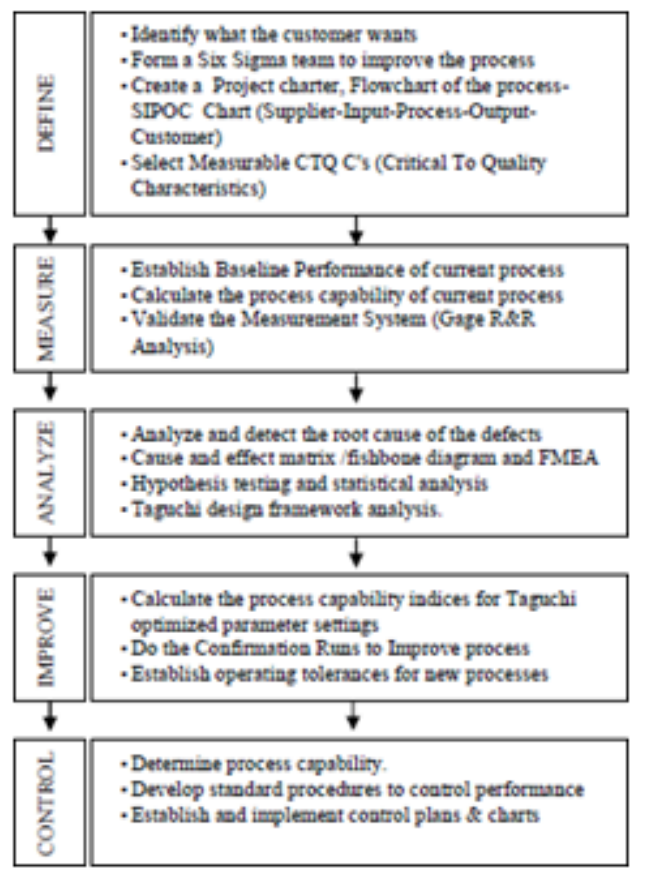

Figure 1 DMAIC activity flow chart

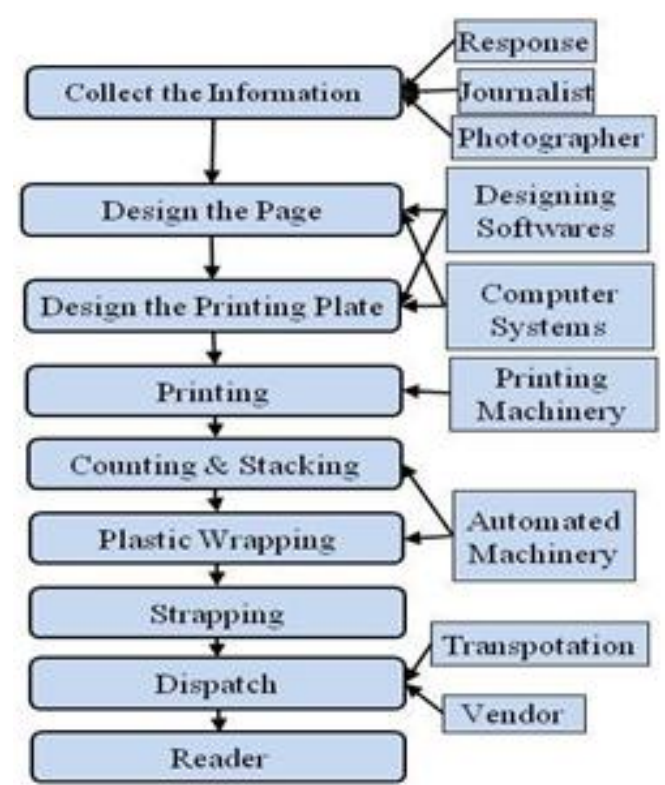

Figure 2 Six sigma flow chart for printing 


\section{CONCLUSION}

Compared to the traditional approach used for printing, we suggest six sigma DMAIC approaches in improving productivity in printing. It has a very bright future space in which to conduct experiments, improvements in many processes in researchareas. In all kinds of companies around the world, printing has already become an important part of manufacturing processes in wide-ranging applications. All these attempts will ultimately increase the percentage of profit and it is possible to optimizewaste.

\section{ACKNOWLEDGMENT}

I would like to thank my guide, Dr. Sachin Lal, for giving me valuable input from time to time and making available all the resources. I would like to thank Sir Padampat University of Singhania, Udaipur for providing all thefacilities required. Finally, heartfelt thanks to all members of my family for their constant encouragement andsupport.

\section{REFERENCES}

[1] H. S. Elsayad \& S. El-sherbiny., A Study into the Influence of Paper Coatings on Paper Properties and Print Quality of Dye Sublimation Thermal Prints. Polymer-Plastics Technology and Engineering, 47(2), 122-136 (2008a).

[2] M. Ataeefard., Influence of paper surface characteristics on digital printing quality. Surface Engineering, Institute of Materials, Minerals and Mining, 30(7), 529-534(2014a).

[3] Nicholas Kingsley Graham Isaac Owusu., Achieving quality in printing: some determining factors in the printing industry in Ghana. The TQM Journal, 27, 6(2015).

[4] Dong Shang Chang, Yi Chun Kuo \& Tz Yu Chen., Productivity measurement of the manufacturing process for outsourcing decisions: the case of a Taiwanese printed circuit board manufacturer. International Journal of Production Research, 46(24), 6981-6995(2008b).

[5] Nazim Emre Islamoglua, Kwangyeol Ryub \& Ilkyeong Moon., Labour productivity in modular assembly: a study of automotive module suppliers. International Journal of Production Research, 1- 17 (2014b).

[6] Pardeep Gupta \& Sachit Vardhan., Optimizing OEE, productivity and production cost for improving sales volume in an automobile industry through TPM: a case study. International Journal of Production Research, 1-13(2016a).

[7] Anupama Prashar., Process improvement in farm equipment sector (FES): a case on Six Sigma adoption. International Journal of Lean Six Sigma, 5(1), 62-88(2014c).

[8] Siddra Qayyum Siddiqui Fahim Ullah Muhammad Jamaluddin Thaheem Hamza Farooq Gabriel., Six Sigma in construction: a review of critical success factors. International Journal of Lean Six Sigma, 7(2), $1-38(2016 b)$.

[9] Ramakrushna Padhy, Six Sigma project selections: a critical review, International Journal of Lean Six Sigma, Vol. 8 Issue: 2, pp.244-258(2016).

[10] Rajesh, N. and Klas, S., Strategic outsourcing through specifications. Omega, 28, 525-540(2000a).

[11] Tomas, F.E.R. and Victor, P.R., A resource-based view of outsourcing and its implications for organizational performance in the hotel sector. Tourism Mgmt., 26, 707-721(2005a).

[12] Tsai, C.Y., Chiu, C.C. and Chen, J.S., A case-based reasoning system for PCB defect prediction. Expert Syst. Appl., 28, 813-822(2005b).

[13] Batool, A. and Batool, B.., Effects of employees training on the organizational competitive advantage: Empirical study of Private Sector of Islamabad, Pakistan, Far East. Journal of Psychology and Business, 6(1), 59-72(2012a).

[14] Beheshti, H. M. and Lollar, J. G.., An empirical study of US SMEs using TQM. Journal of TQM and Business Excellence, 14(8), 839-847 (2003a).

[15] Curkovic, S., Melnyk, S., Calantone, R. and Handfield, R.., Validating the Malcolm Baldrige National quality award framework through structural equation modelling. International Journal of Production Research, 38(4), 765-791(2000b).
[16] Daily, B. F. and Bishop, J. W.., TQM Workforce and Employee Involvement: The Pivotal Role of Teamwork. Journal of Managerial Issues, 15(4), 393-412(2003b).

[17] Graham, N. K., Arthur, Y. D. and Mensah, D. P.., Managerial role in ensuring successful total quality management programme in Ghanaian printing firms. The TQM Journal, 26(5), 398-410 (2014c).

[18] Denham Lincoln, N., Travers, C., Ackers, P. and Wilkinson, A., The meaning of Empowerment: The Interdisciplinary Etymology of a New Management Concept. International Journal of Management Reviews, 4(3), 271-290(2002).

[19] Karia, N. and Asaari, M. H. A. H., The effects of total quality management practices on employees work-related attitudes. The TQM Magazine, 18(1), 30-43(2006a).

[20] Palo, S. and Padhi., Measuring Effectiveness of TQM Training: an Indian study. International Journal of Training and Development, 7(3), 203-216(2003c).

[21] Rahman, Z. and Siddiqui, J., Exploring total quality management for information systems in Indian firms: Application and benefits. Business Process Management Journal, 12(5), 622-631(2006b)

[22] Saravanan, R. and Rao, K. S. P.., Development and validation of an instrument for measuring Total Quality Service. Total Quality Management, 17(6), 733-749(2006c).

[23] Talib, F., Rahman, Z. and Qureshi, M. N.., Pareto analysis of total quality management factors critical to success for service Industries. International Journal for Quality Research, 4(2), 155-168 (2010).

[24] Zakuan, N., Muniandy, S., Mat Saman, M. Z., Md Ariff, M. S., Sulaiman, S. and Abd Jalil, R.., Critical Success Factors of Total Quality Management Implementation In Higher Education Institution: A Review. International Journal of Academic Research in Business and Social Sciences, 2(12), 19-32 (2012b).

[25] Zhang, Z.., Quality Management Worldwide: Quality Management Approach in China. The TQM Magazine, 12(2), 44-48(2000c).

[26] Ahuja, I. P. S., and J. S. Khamba., Strategies and Success Factors for Overcoming Challenges in TPM Implementation in Indian Manufacturing Industry. Journal of Quality in Maintenance Engineering, 14(2), 123-147(2008).

[27] Hemanand, K., D. Amuthuselvan, S. C. Raja, and G. Sundararaja, Improving Productivity of Manufacturing Division using Lean Concepts and Development of Material Gravity Feeder-a Case Study. International Journal of Lean Thinking, 3(2), 117-134(2012c).

[28] Tsarouhas, P. H.,. Evaluation of Overall Equipment Effectiveness in the Beverage Industry: A Case Study. International Journal of Production Research, 51(2), 515-523(2013).

[29] Wakjira, M. W., A. P. Singh,. Total Productive Maintenance: A Case Study in Manufacturing Industry. Global Journal of Researches in Engineering Industrial Engineering, 12(1), 25-32 (2012d).

[30] Wudhikarn, R.,. Improving Overall Equipment Cost Loss Adding Cost of Quality. International Journal of Production Research, 50(12), 3434-3449(2012e).

[31] Zammori, F.,. Fuzzy Overall Equipment Effectiveness (FOEE): Capturing Performance Fluctuations through LR Fuzzy Numbers. Production Planning \& Control, 26(6), 451-466 (2014d). 